Scientific paper

\title{
Properties of Methanol-Water Mixtures in a Coarse-Grained Model
}

\author{
Matej Huš, ${ }^{1,2}$ Gašper Žakelj ${ }^{1}$ and Tomaž Urbič ${ }^{1, *}$ \\ ${ }^{1}$ University of Ljubljana, Faculty of Chemistry and Chemical Technology, Chair of Physical Chemistry, \\ Večna pot 113, SI-1000 Ljubljana, Slovenia \\ 2 National Institute of Chemistry, Laboratory of Catalysis and Chemical Reaction Engineering, \\ Hajdrihova ulica 19, SI-1000 Ljubljana, Slovenia \\ *Corresponding author: E-mail: tomaz.urbic@fkkt.uni-lj.si
}

Received: 19-02-2015

Dedicated to Prof. Dr. Jože Koller on the occasion of his $70^{\text {th }}$ birthday.

\begin{abstract}
Methanol and water rank among the most important liquids in modern world due to their versatile use. As water, methanol and their mixtures exhibit numerous anomalous properties, their description is challenging. The amphiphilic nature of methanol causes its aqueous solutions to have negative excess volume and enthalpy across the entire composition range. A simple isotropic water model and its coarse-grained extension were used to study the properties of methanol and water-methanol mixtures. Using Monte Carlo simulations, we showed that the model correctly describes the thermodynamic properties of methanol, density dependence of water-methanol mixtures upon temperature and composition, and excess properties of mixtures. Although no conscious effort was made to fine-tune the potential, the results are remarkably close to experimental data.
\end{abstract}

Keywords: isotropic models, Monte Carlo simulations, methanol-water mixtures, non-ideality

\section{Introduction}

Water, methanol and especially their solutions find abundant use in everyday life. They are used in medical and personal care products, food industry, transportation, chemical industry etc. Their roles comprise a broad spectrum as they can be valuable as reagents, solvents, antifreeze, raw materials and cleaning agents. ${ }^{1-3}$ Methanol can also be used as fuel. ${ }^{4}$ It is therefore important to understand their behaviour on the molecular scale.

Methanol and water share many properties due to their similarity on the molecular scale. Both are of comparable size, have comparable dipole moment and participate in hydrogen bonding. Consequently, they are fully miscible. Water, however, displays more anomalous properties due to stronger hydrogen bonding. The methyl group in methanol is weakly polar and diminishes the polar nature of the compound.

Water exhibits the temperature of maximum density at $4{ }^{\circ} \mathrm{C}$ at normal pressure, while methanol does not. Ice floats on water due to lesser density, while solid methanol sinks. Both, methanol and water, have higher boiling points than anticipated for the molecules of their size.
Methanol melting point, however, is much more depressed than that of water. The dielectric constant of methanol is also considerably lower than in water. ${ }^{5-7}$

Water is usually described with models that deal with atoms and electronic pairs explicitly. Among the most popular models are SPC or TIP5P that perform remarkably well near ambient conditions. Analogously, methanol can be modelled explicitly with models, such as optimized potential for liquid simulations (OPLS), ${ }^{8} \mathrm{~L} 1$ model, ${ }^{9} \mathrm{H} 1{ }^{10,11}$ model or L2 model. ${ }^{12,13}$ These models are particularly useful when water or methanol is a medium and not the investigated substance, per se. In the latter case, simpler models are sometimes needed. These models may not reproduce experimentally measured properties verbatim, but on the other hand offer a chance to systematically study those properties, as there are fewer parameters that can be adjusted. ${ }^{14,15}$

Coarse-grained models have been shown to describe the thermodynamic and structural properties of water surprisingly well. Although transferability ${ }^{16}$ and reproducibility issues ${ }^{17}$ hinder the determination of a complete panel of properties, it is still possible to extract a myriad of useful information. Examples of such isotropic potentials are repul- 
sive shoulder potential,${ }^{18}$ honeycomb potential,${ }^{19}$ LennardJones-Gaussian potential, ${ }^{20,21}$ Jagla potential ${ }^{22,23,24}$ and the continuous shouldered well (CSW) potential. ${ }^{25}$ Methanol can be modelled with attaching a second bead to a particle with the aforementioned pair potential. ${ }^{26-29}$

In our work, we studied the properties of water-methanol mixtures with the Monte Carlo simulation method. A simple coarse-grained isotropic potential was used for water, while methanol was modelled with two-bead particles. After comparing calculated thermodynamic properties of pure methanol with the experimental data, density, excess volume and excess enthalpy of mixtures were systematically studied at various compositions and temperatures.

This paper consists of five sections. In Section II, the model is outlined. Section III deals with the theoretical background and simulation details, with results and discussion following in the Section IV. A short conclusion in Section V completes the paper.

\section{The Model}

To model methanol the two groups that form the molecule were treated separately. Atoms of the hydroxyl group $(\mathrm{OH})$ were absorbed into a pseudoatom with CSW pair interaction

$$
\begin{aligned}
U_{11}(r)= & \frac{U_{R}}{1+\exp \left(\Delta \frac{\left(r-R_{R}\right)}{a}\right)}-U_{A} \exp \\
& +U_{A}\left(\frac{a}{r}\right)^{24}
\end{aligned}
$$

This function can be viewed as the sum of a soft repulsive shoulder of height $U_{R}$, an attractive Gaussian well of depth $\mathrm{U}_{\mathrm{A}}$ and width $2 \delta_{A} \sqrt{2 \ln 2}$, and a steep repulsive wall. $R_{R}$ and $R_{A}$ are the repulsive average radius and the distance of the attractive minimum, respectively. The repulsive shoulder steepness is determined by the parameter $\Delta$ and the $\delta_{A}^{2}$ represents Gaussian variance. In our work, we used the following parameters: $U_{R} / U_{A}=2, R_{R} / a=1.6, R_{A} / a$ $=2,\left(\delta_{A} / a\right)^{2}=0.1, \Delta=15$.

Atoms of the methyl group $\left(\mathrm{CH}_{3}\right)$ form the other pseudoatom. The hydrophobic character of this groups is taken into account with the modified Lennard-Jones pair potential

$$
U_{22}(r)=\frac{4}{3} 2^{2 / 3} \varepsilon_{22}\left[\left(\frac{\sigma_{22}}{r}\right)^{24}-\left(\frac{\sigma_{22}}{r}\right)^{6}\right]
$$

We have set $\sigma_{22} / a=1.0$ and $\varepsilon_{22} / U_{A}=0.1$, effectively making the hydroxyl and methyl groups of the same size and methy-methyl interactions $90 \%$ weaker than the hydrogen bonding in water.

Mixed interaction $\left(U_{12}\right)$ was calculated from the same equation with altered parameters. Parameters descri- bing the interaction strength $(\varepsilon)$ and bond length $(\sigma)$ are derived from Berthelot-Lorentz rules: $\varepsilon_{12}=\sqrt{\varepsilon_{22} U_{A}}$ and $\sigma_{12}=0.5\left(\sigma_{22}+a\right)$. Water was modelled as a lone hydroxyl group. Methyl group and hydroxyl group were fixed in a tangential position (see Figure 1). See Figure 2 for details on potential functions.

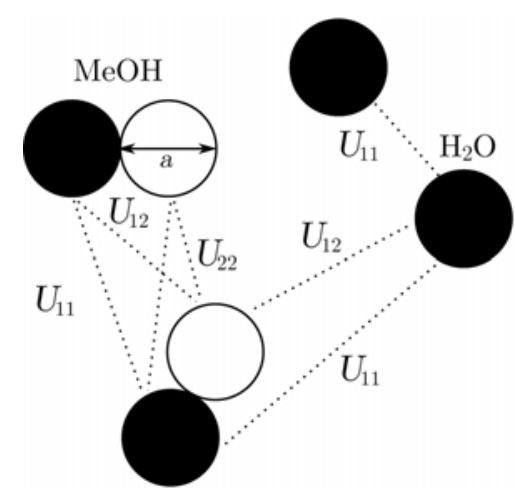

Figure 1: Methanol is modelled as two tangential spheres, representing the hydroxyl (black) and methyl (white) groups. Water is modelled as a sphere (black). Interactions between black particles is described by the CSW potential, other interactions are LennardJonesian.

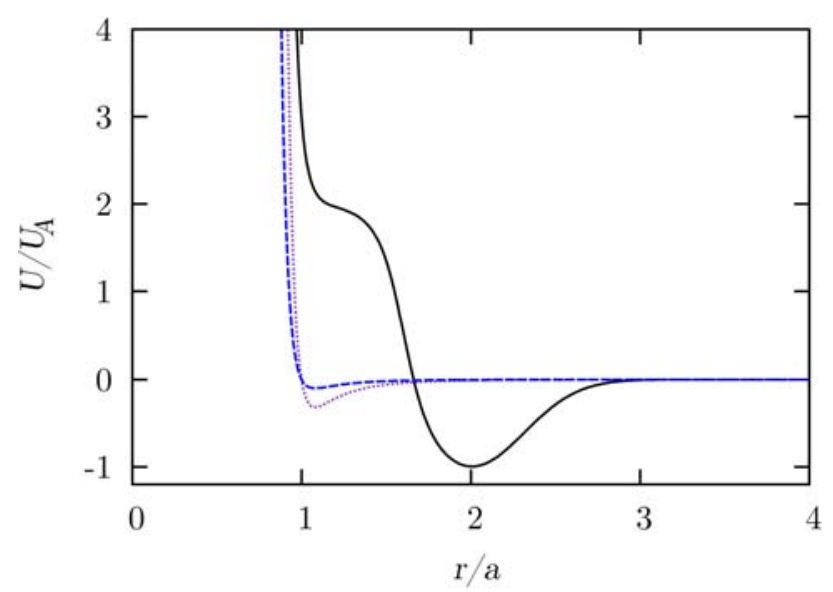

Figure 2: Pair interaction between hydroxyl/water pseudoatoms (solid line), between methyl pseudoatoms (dashed lines) and mixed interaction (dotted line).

\section{Simulation Details}

Monte Carlo simulations were performed in the isothermal-isobaric (NPT) ensemble in a cubic box with periodic boundary conditions and minimum image convention. Each time, a total of 500 particles were introduced in a box. The relative proportion of methanol and water particles was adjusted according to their respective molar masses $\left(M_{\text {methanol }}=32, M_{\text {water }}=18\right)$.

Simulations were performed at a constant pressure $p^{*}=0.018$, which is below the critical point for both pure water and pure methanol. We limited our study to the li- 
quid portion of the phase diagram, i.e. $0.5<T^{*}<1.0$. Equilibration part of the simulation consisted of 100000 cycles and was followed by five sampling runs of 100000 cycles. One cycle corresponded to an attempted displacement of every particle, one attempted rotation of each methanol molecule around a randomly chosen axis and one attempted change of the box size. Maximum displacement, rotation and resize factor were dynamically adjusted during the equilibration to reach $50 \%$ acceptance ratio.

Numerical density was calculated as inverse average volume per particle, N/V. Coefficients of thermal expansion, isothermal compressibility and heat capacity were calculated from fluctuations as

$$
\begin{gathered}
\alpha=\frac{\langle H V\rangle-\langle H\rangle\langle V\rangle}{\left.T^{2}<V\right\rangle} \\
k=\frac{\left\langle V^{2}\right\rangle-\langle V\rangle\langle\boldsymbol{V}\rangle}{T<V\rangle} \\
c_{p}=\frac{\left\langle H^{2}\right\rangle-\langle H\rangle\langle H\rangle}{k_{B} T^{2}}
\end{gathered}
$$

Results are reported in dimensionless reduced units, relative to the diameter of hydroxyl group and the depth of its attractive well: $T^{*}-\frac{k_{b} T}{U_{A}}, \rho^{*}=\rho a^{\mathbf{3}}$ and $p^{*}-\frac{p a^{3}}{U_{A}}$. For the analysis of the mixture data, methanol weight fraction was used as a controlled variable.

\section{Results And Discussion}

\section{1. Parameterisation Considerations}

Parameterisation of the water particles, interacting with CSW potential, was kept unchanged from Franzese ${ }^{25}$ and our previous work. ${ }^{26,27}$ As it has been previously proved that is in qualitative and semi-quantitative agreement with experimental data for real water, this is a reasonable assumption. To describe methanol in the extended CSW model, three additional parameters are needed: LennardJones attraction well depth and location, and the distance between hydroxyl and methyl group. Their values (see Section III) were are the same as in our previous work to make comparisons possible.

\section{2. Methanol Thermodynamics}

In Figure 3, we compare real methanol thermodynamics from experimental data ${ }^{30,31}$ (panels a-d) with model predictions (panels $\mathrm{e}-\mathrm{h}$ ). Model data were collected at subcritical pressure $\left(\mathrm{p}^{*}=0.018\right)$ in the temperature range $0.45<\mathrm{T}^{*}<1.0$, where the model methanol is liquid. Specific volume (inverse of density) increases linearly with temperature, showing no density anomaly. Model data reproduce this behaviour rather well, although the slope gets larger at higher temperatures. The thermal expansion coefficient in methanol has a shallow minimum around $\mathrm{T}=-40{ }^{\circ} \mathrm{C}$, which our model fails to predict. Isothermal compressibility increases monotonically with temperature in both the experiment and the model. Heat capacity also increases with temperature, again evidenced by real data and displayed in our model.

\section{3. Water/methanol Mixtures}

First, we investigate how the molecular structure of the mixture changes as the methanol fraction is increased. Figures $4 \mathrm{a}$ and Figure $4 \mathrm{~b}$ show hydroxyl-water and methyl-water pair distribution functions (PDF), respectively, at $\mathrm{T}^{*}=0.60$ and $\mathrm{p}^{*}=0.018$. Although weight fraction of methanol changes from $20 \%$ to $80 \%$, no major change in PDF is encountered. There is a very slight increase of the peaks and decrease of the troughs, suggesting greater order, as the methanol fraction is increased. Effect is consistent across the whole composition range, but is very small in magnitude. In Figure $4 c$, all possible combinations of PDFs are shown, all for $\mathrm{wt}(\mathrm{MeOH})=0.4$. As expected due to similar potential functions used, the hydroxyl group and water molecule behave similarly and have almost coinciding PDFs (hydroxyl-hydroxyl, hydroxyl-water, water-water). Methyl-methyl PDF has the fewest and the smallest peaks, as methyl groups are not particularly organised due to weak interactions.

Density of methanol is lower than that of water and shows no temperature maximum. Consequently, densities of mixtures must decrease as the fraction of methanol increases. Additionally, there must exist a composition, where the density maximum vanishes. Experimental data have shown it is located slightly below $10 \%$ wt methanol. Figures $5 \mathrm{a}$ and $5 \mathrm{~b}$ show the temperature and composition dependence of mixture densities, while Figures $5 \mathrm{~d}$ and $5 \mathrm{e}$ show model predictions. Trends are in overall agreement, although there are some discrepancies. Most pronouncedly, the model predicts the density to increase with increasing methanol fraction at low temperatures and low methanol fraction. In reality, this effect is very small and confined to very low temperatures and is not nearly as strong. In the model (Figure 5f), the density maximum shifts to lower temperature as methanol fraction is increased and disappears altogether around $40 \% \mathrm{wt}$, while the experimental results show the same trend (Figure 5e).

Nonideality of mixtures of water and methanol can be described by excess volume and excess enthalpy of mixing. Attractive forces between molecules dominate and cause the solution to shrink, compared to the volume of the ideal mixture. The excess volume was calculated as $\Delta V=\frac{\Delta Y}{x V_{m}+(1-x) V_{w}}$, where $\mathrm{V}_{\mathrm{m}}$ and $\mathrm{V}_{\mathrm{w}}$ are molar volu- 
a)

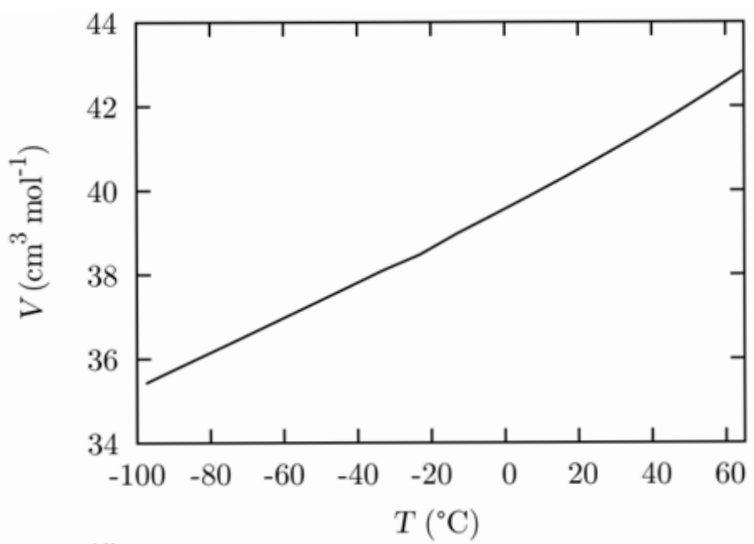

b)

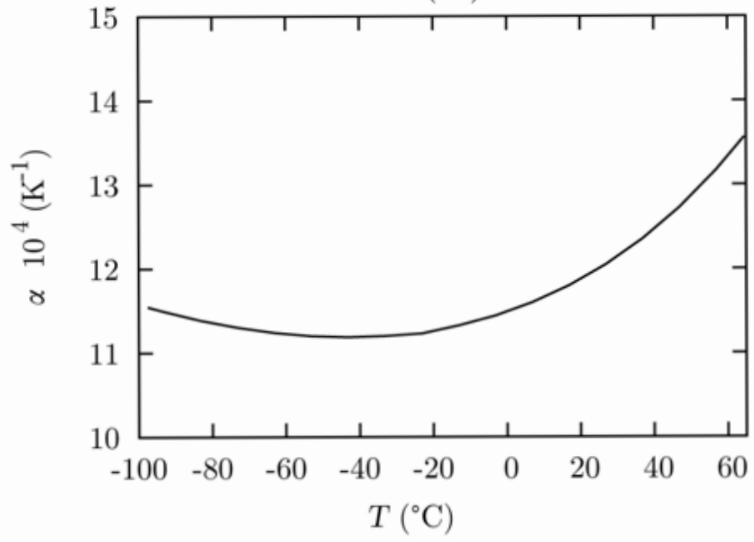

c)

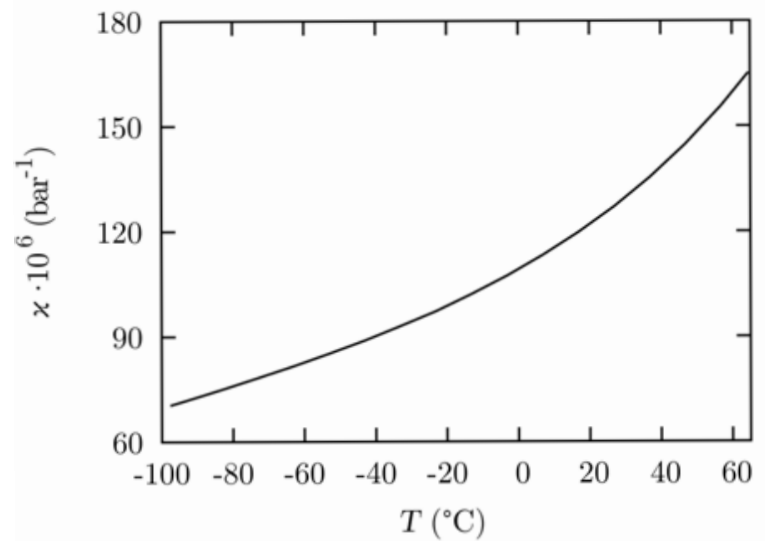

d)

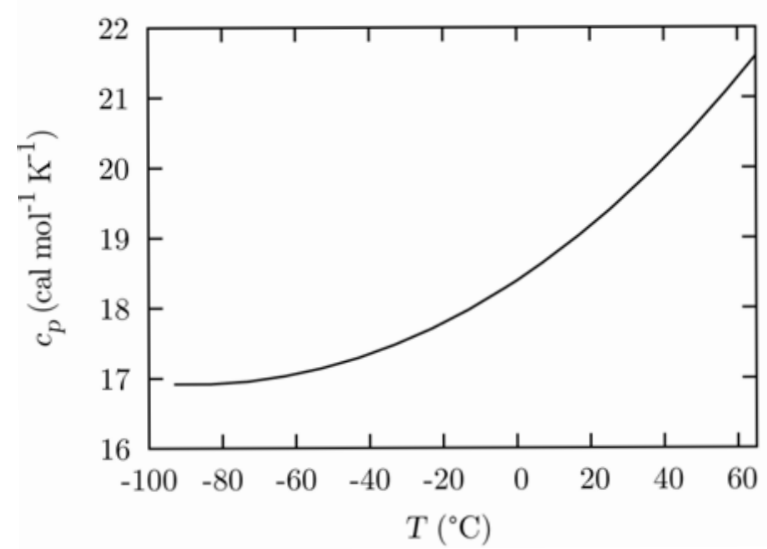

e)

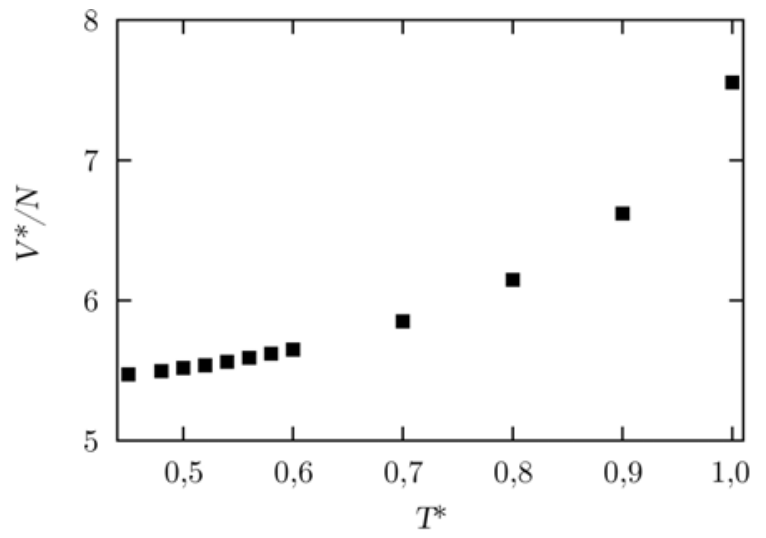

f)

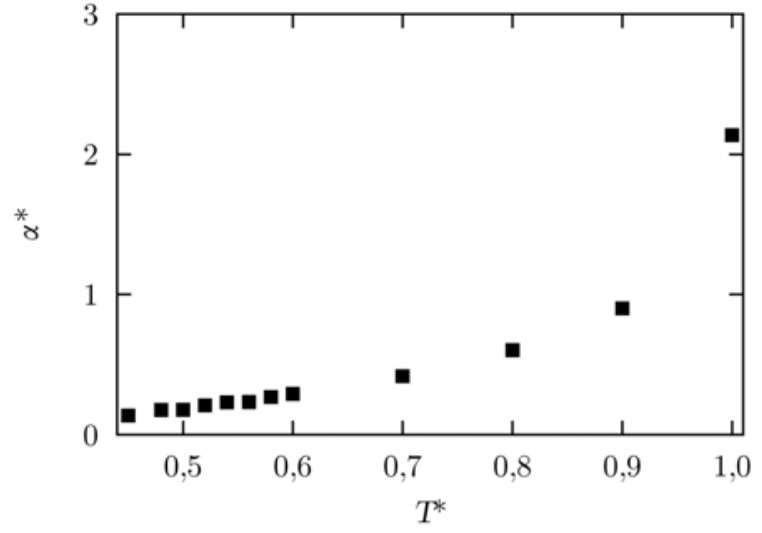

g)

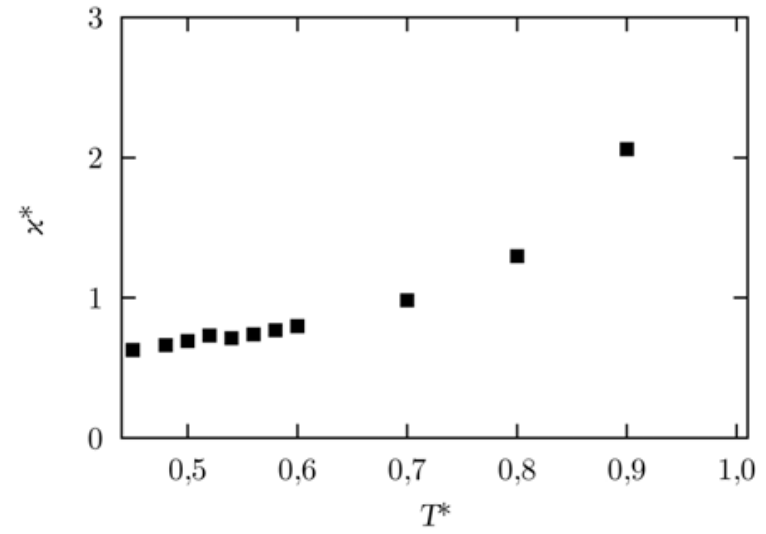

h)

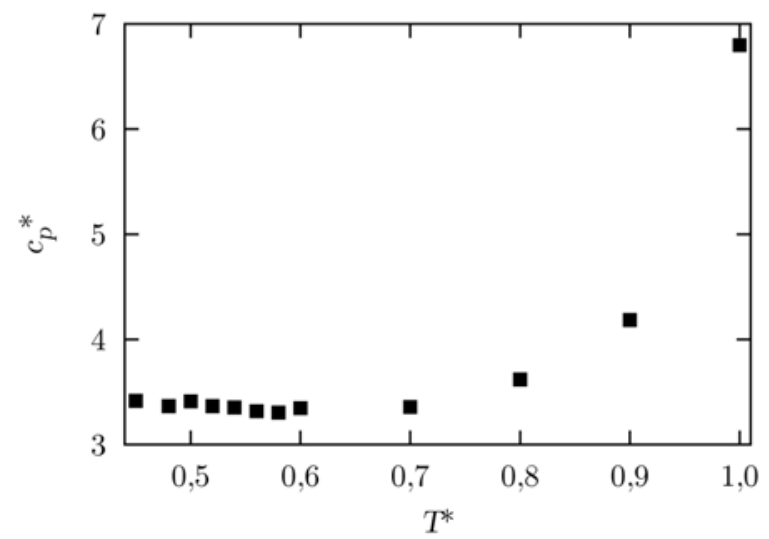

Figure 3: Thermodynamic properties of pure methanol at 1 atm (panels a-d) and results from the model (e-h) at subcritical pressure $\mathbf{p}^{*}=\mathbf{0 . 0 1 8}$ follow matching trends. 
a)

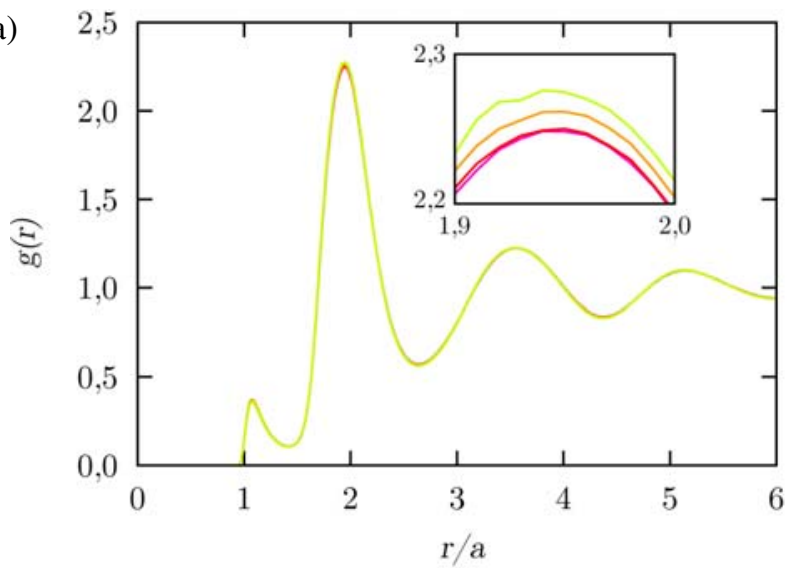

b)

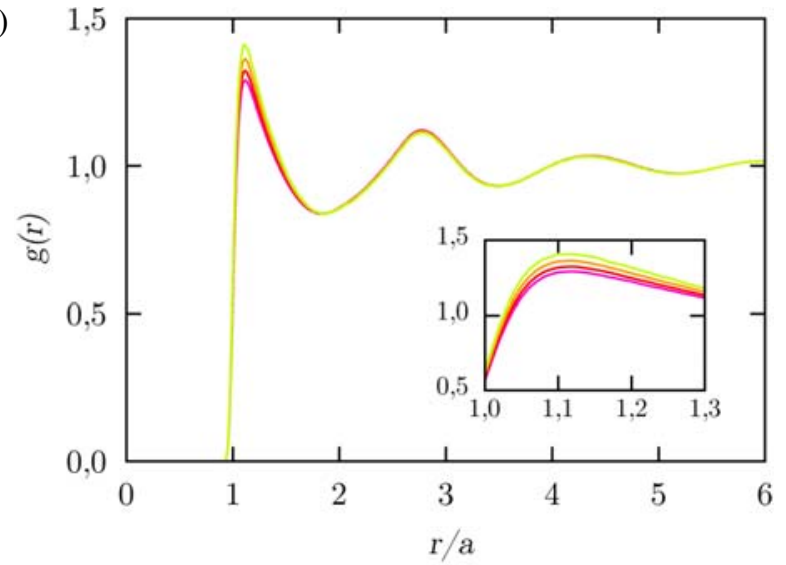

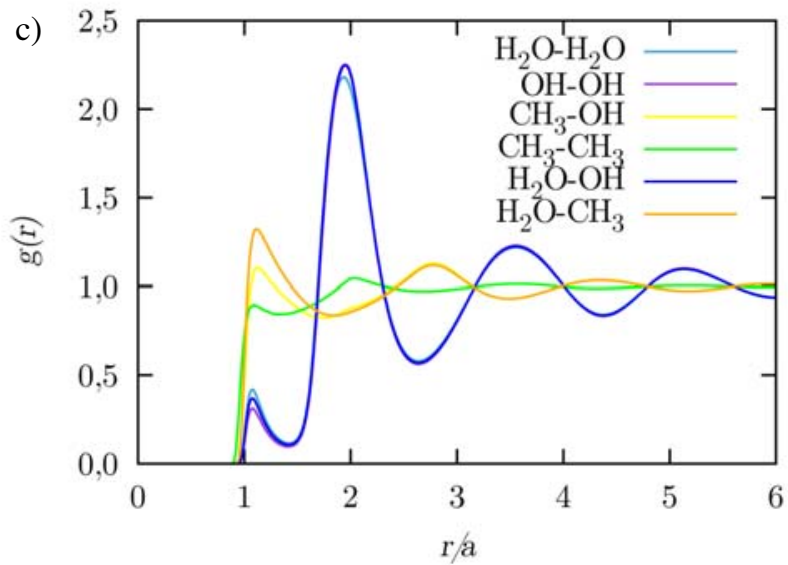

Figure 4: Pair distribution functions in water/methanol mixtures at $\mathrm{T}^{*}=0.6$ for different mass fractions of methanol $-20 \%$ (pink), $40 \%$ (red), 60 (yellow) $\%, 80 \%$ (green) - as predicted by our model. Hydroxyl-water (panel a) and methyl-water (panel b) functions are weakly dependent on the methanol fraction. Panel c shows comparison with intraspecies methanol and water distribution function.

mes of pure methanol and water, respectively, at the corresponding temperature, and $x$ molar fraction of methanol. The numerator is calculated as $\Delta Y=\frac{V_{m i x}-\left(n_{w} V_{w}+n_{m} V_{m}\right)}{n_{w}+n_{m}}$, where $\mathrm{V}_{\text {mix }}$ is molar volume of the mixture, and $\mathrm{n}_{\mathrm{w}}$ and $\mathrm{n}_{\mathrm{m}}$ number of water and methanol particles, respectively. As this value is dimensionless, model data can be directly compared with experimental values, ${ }^{32}$ as shown in Figure 6 . The model correctly predicts negative excess volume, but the magnitude of the effect is too small. This agreement could be improved with a reparameterisation.

Excess enthalpy was calculated as $\Delta H_{s}=\frac{H_{(x)}-x H_{m}-(1-x) H_{w}}{V_{w(x)+} V_{m(x)}}$, where $\mathrm{H}(\mathrm{x})$ is the enthalpy of the system when the molar fraction of methanol equals $x, \mathrm{H}_{\mathrm{m}}$ is the enthalpy of pure methanol and $\mathrm{H}_{\mathrm{w}}$ enthalpy of pure water. Enthalpy of the system is calculated as the sum of pair interactions and the $\mathrm{P}^{*} \mathrm{~V}$ term. Figure 7 shows the model results juxtaposed with the experimental data ${ }^{33}$ on secondary axis. For higher temperatures, the trend is quantitatively correct, showing negative excess enthalpy of mixing with a pronounced minimum near $\mathrm{x}=0.4$. At low temperatures, the trend reverses.

\section{Conclusion}

We have extended the CSW model, originally designed to describe water, to methanol particles. Tangentially joining two beads, one having the CSW pair potential and the other one having a modified Lennard-Jones potential, the model was deemed to correspond to methanol.

To get a basic overview of the model abilities, we calculated the thermodynamic properties of pure methanol and compared them with experimental data, where good agreement was found. Additionally, we compared the structure and ordering of particles at various compositions and found the effect to be negligible. Density, excess volume and excess enthalpy were studied as functions of temperature and composition, showing surprisingly good qualitative agreement with experimental data. Excess enthalpy was reproduced somewhat worse, probably owing to the fact that the hydroxyl group and water potential should have been modelled differently. Had we tried to tweak the potential parameters any further, we believe we could have quantitatively improved the agreement with the experimental data. 
a)

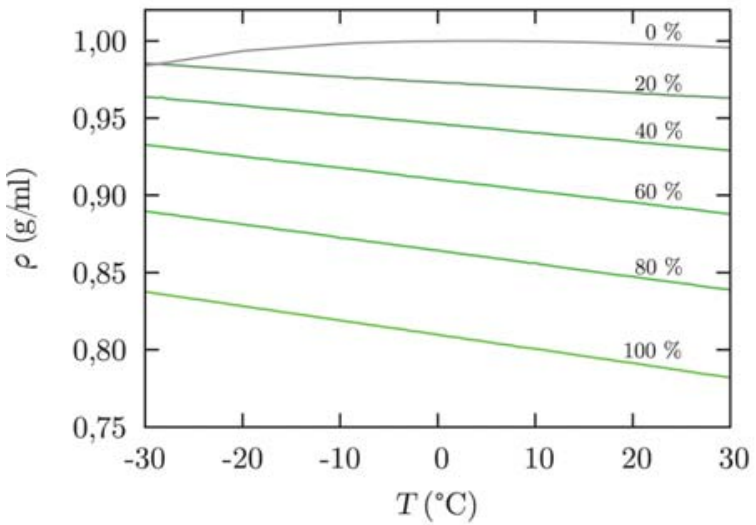

b)

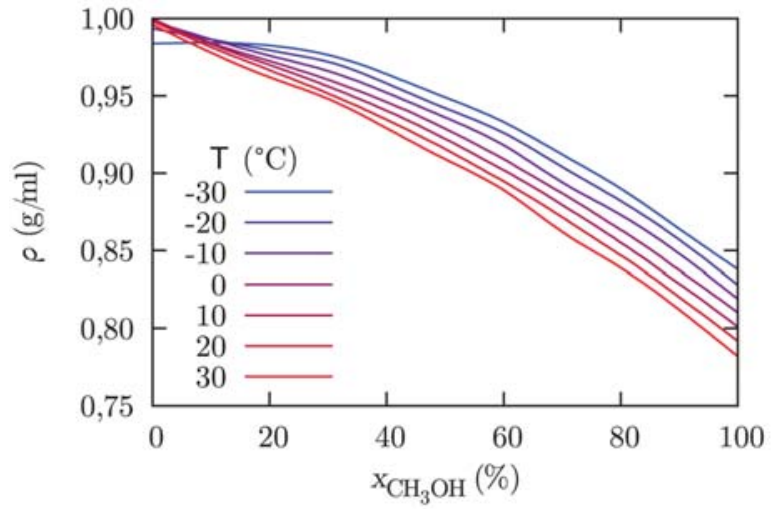

c)

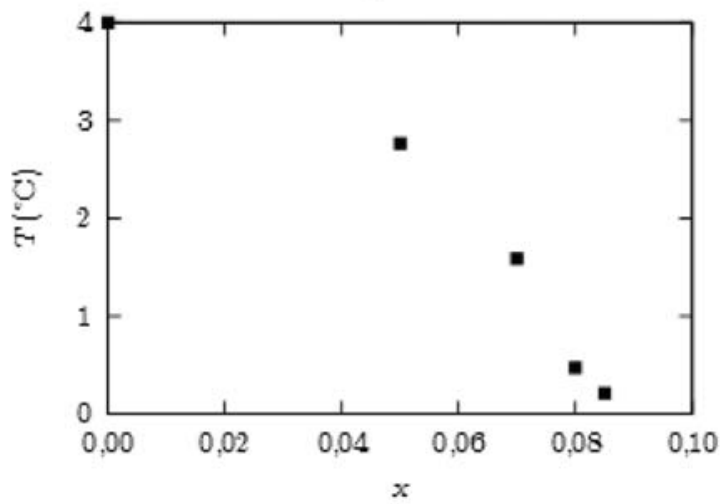

d)

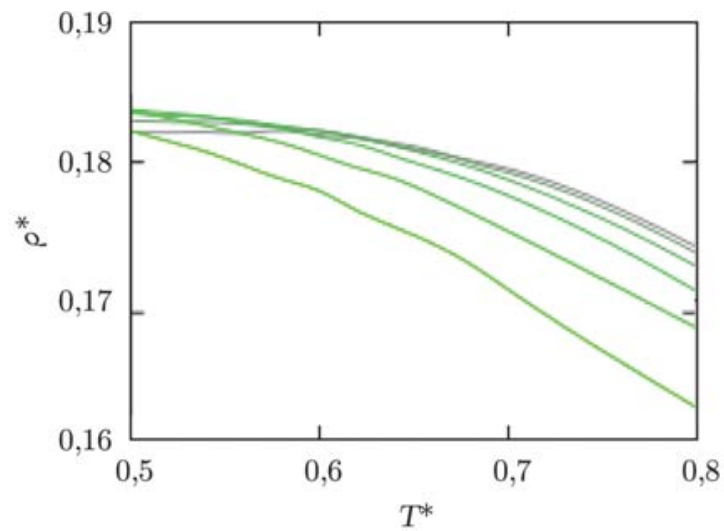

e)

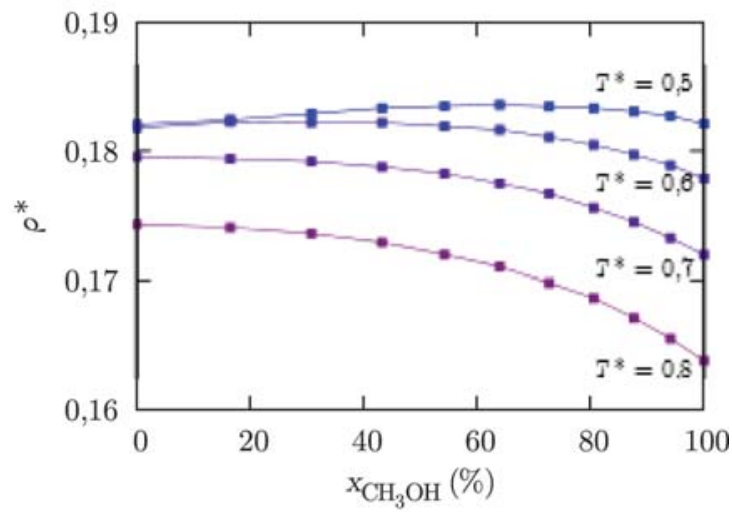

f)

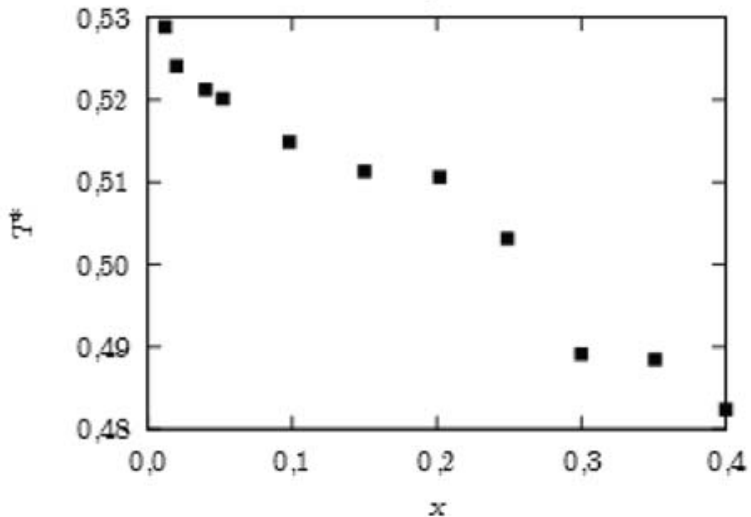

Figure 5: Density of methanol/water mixtures at $1 \mathrm{~atm}$ as a function of temperature and composition (mass fraction of methanol), and the temperature of maximum density. Experimental results (panels a-c) and model results (panels $d-f$ ) show the same trends.

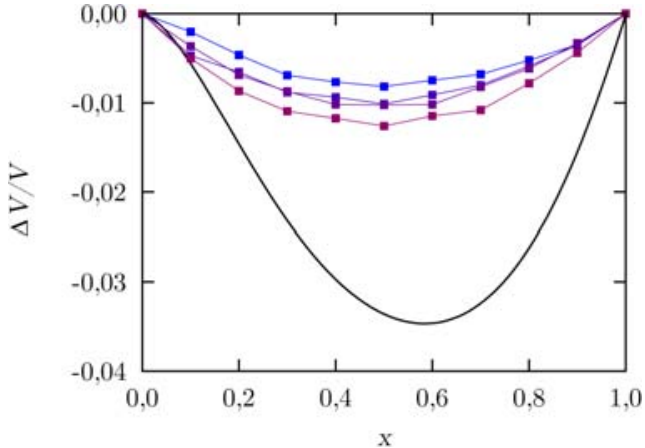

Figure 6: Excess volume as a function of mass fraction of methanol. Symbols represent simulation results at $\mathrm{T}^{*}=0.5$ (blue), $0.6,0.7$ and 0.8 (red) and $\mathrm{p}^{*}=0.018$ with connecting lines as guides-for-eye. Solid continuous line represents experimental data at $20^{\circ} \mathrm{C}$ and $1 \mathrm{~atm}$.

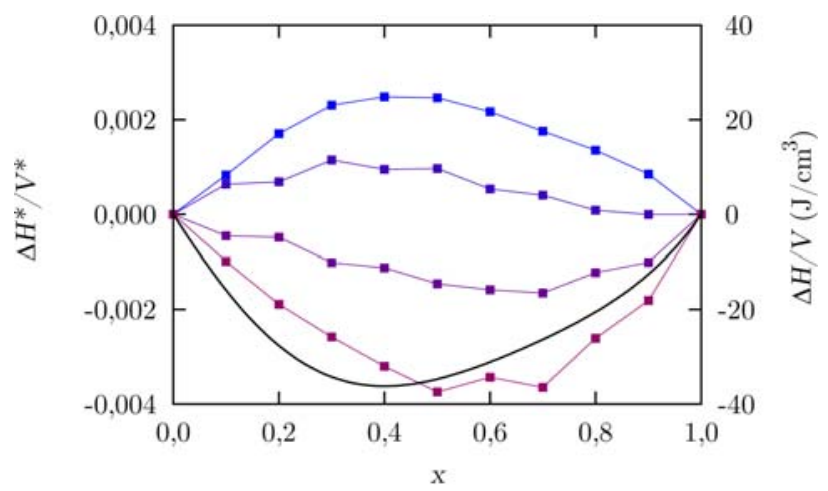

Figure 7: Excess enthalpy of mixing as a function of mass fraction of methanol. Legend as in Figure 6. 
Temperature of the maximum density was shown to decrease with increasing fraction of methanol. It disappears at around $40 \%$ of methanol, which is somewhat greater than in experimental data.

\section{Acknowledgements}

Financial support from Slovenian Research Agency through grant P1 0103-0201 and the Young Researcher programme is appreciated.

\section{References}

1. G. A. Olah. Angew. Chem. Int. Ed. 2005, 44, 2636-2639. http://dx.doi.org/10.1002/anie.200462121

2. C. B. Xiao, and H. Bianchi, and P. R. Tremaine, J. Chem. Thermdyn. 1997, 29, 261-286. http://dx.doi.org/10.1006/jcht.1996.0145

3. T. Sato, A. Chiba, and R. Nozaki, J. Chem. Phys. 2000, 112, 2924-2932. http://dx.doi.org/10.1063/1.480865

4. S. Wasmus and A. Küver, J. Electroanal. Chem. 1999, 461, 14-31. http://dx.doi.org/10.1016/S0022-0728(98)00197-1

5. D. Eisenberg and W. Kauzmann, The Structure and Properties of Water, $1^{\text {st }}$ ed. 1969, Oxford University Press, Oxford.

6. F. Franks and D. S. Reid, Water. A Comprehensive Treatise, $1^{\text {st }}$ ed., 1973, Plenum Press, New York.

7. A. P. Gregory and R. N. Clarke. Meas. Sci. Technol. 2005, 16, 1506-1516. http://dx.doi.org/10.1088/0957-0233/16/7/013

8. W. L. Jorgensen, J. Phys. Chem. 1986, 90, 1276-1284. http://dx.doi.org/10.1021/j100398a015

9. M. E. van Leeuwen and B. Smit, J. Phys. Chem. 1995, 99, 1831-1833. http://dx.doi.org/10.1021/j100007a006

10. M. Haughney, M. Ferrario, and I. R. McDonald, Mol. Phys. 1986, 58, 849-853. http://dx.doi.org/10.1080/00268978600101611

11. M. Haughney, M. Ferrario, and I. R. McDonald, J. Phys. Chem. 1987, 91, 4934-4940. http://dx.doi.org/10.1021/j100303a011

12. T. Schnabel, A. Srivastava, J. Vrabec, and H. Hasse, J. Phys. Chem. B 2007, 111, 9871-9878. http://dx.doi.org/10.1021/jp0720338

13. G. Guevara-Carrion, C. Nieto-Draghi, J. Vrabec, and H. Hasse, J. Phys. Chem. B 2008, 112, 16664-16674. http://dx.doi.org/10.1021/jp805584d

14. S. Izvekov, G. A. Voth. J. Phys. Chem. B 2005, 109, 24692473. http://dx.doi.org/10.1021/jp044629q

15. G. J. Tóth. Phys. Condens. Matter 2007, 19, 335222. http://dx.doi.org/10.1088/0953-8984/19/33/335222

16. M. E. Johnson, T. Head-Gordon, A. A. Louis, J. Chem. Phys. 2007, 126, 144509. http://dx.doi.org/10.1063/1.2715953

17. A. Chaimovich, M. S. Shell, Phys. Chem. Chem. Phys. 2009, 11, 1901-1915. http://dx.doi.org/10.1039/b818512c

18. Y. D. Fomin, E. N. Tisok, V. N. Ryzhov, J. Chem. Phys. 2011, 135, 124512. http://dx.doi.org/10.1063/1.3643115

19. S. Zhou, J. Chem. Phys. 2010, 133, 134107. http://dx.doi.org/10.1063/1.3486570

20. A. B. de Oliveira, P. A. Netz, T. Colla, M. C. Barbosa, J. Chem. Phys. 2006, 124, 084505. http://dx.doi.org/10.1063/1.2168458

21. W. P. Krekelberg, T. Kumar, J. Mittal, J. R. Errington, T. M. Truskett, Phys. Rev. E 2009,79, 031203. http://dx.doi.org/10.1103/PhysRevE.79.031203

22. S. V. Buldyrev, P. Kumar, P. G. Debenedetti, P. J. Rossky, and H. E. Stanley, Proc. Natl. Acad. Sci. U.S.A. 2007, 104, 20177-20182. http://dx.doi.org/10.1073/pnas.0708427104

23. E. A. Jagla, J. Chem. Phys. 1999, 111, 8980. http://dx.doi.org/10.1063/1.480241

24. L. Xu, S. V. Buldyrev, C. A. Angell, H. E. Stanley, Phys. Rev. E 2006, 74, 031108. http://dx.doi.org/10.1103/PhysRevE.74.031108

25. G. Franzese, J. Mol. Liq. 2007, 136, 267-273. http://dx.doi.org/10.1016/j.molliq.2007.08.021

26. M. Huš, G. Munao, T. Urbic. J. Chem. Phys. 2014, 141, 164505. http://dx.doi.org/10.1063/1.4899316

27. M. Huš, T. Urbic. Phys. Rev. E. 2014, 90, 062306. http://dx.doi.org/10.1103/PhysRevE.90.062306

28. Z. Su, S. V. Buldyrev, P. G. Debenedetti, P. J. Rossky, H. E. Stanley. J. Chem. Phys. 2012, 136, 044511. http://dx.doi.org/10.1063/1.3677185

29. B. Hribar-Lee, K. A. Dill. Acta Chim. Slov. 2006, 53, 257263.

30. R. D. Goodwin, J. Phys. Chem. Ref. Data 1987, 16, 799-892. http://dx.doi.org/10.1063/1.555786

31. M. Zábranský, V. Ružička Jr. and V. Majer, J. Phys. Chem. Ref. 1990, 19, 719-762.

32. G. C. Benson and O. Kiyohara. J. Sol. Chem. 1980, 9, 791-804. http://dx.doi.org/10.1007/BF00646798

33. R. F. Lama and B. C.-Y. Lu, J. Chem. Eng. Data 1965, 10, 216-219. http://dx.doi.org/10.1021/je60026a003

\section{Povzetek}

Metanol in voda zaradi svoje uporabnosti sodita med najpomembnejši tekočini v modernem svetu. Ker voda, metanol in njune mešanice izkazujejo številne anomalne lastnosti, predstavlja njihov opis velik izziv. Amfifilna narava metanola je razlog, da imajo njegove vodne raztopine negativni presežno prostornino in entalpijo v vseh sestavah. Za proučevanje lastnosti metanola ter mešanic vode in metanola smo uporabili enostaven izotropni model vode in njegovo grobo-zrnato razširitev. S simulacijami Monte Carlo smo pokazali, da model pravilno opiše termodinamične lastnosti metanola, odvisnost gostote mešanice vode in metanola od temperature in sestave ter presežne lastnosti mešanic. Čeprav potenciala nismo posebej prilagajali, so rezultati presenetljivo blizu eksperimentalnim podatkom. 